\title{
Metal Fractionation in Soil Profiles in Umutu Oil Field, Northwest Niger Delta Nigeria
}

\author{
Edwin O. Adaikpoh \\ Department of Geology, Delta State University \\ Abraka. PMB 1. Abraka. Delta State, Nigeria \\ Tel: 234-803-727-4021_E-mail: adaikpoh_edwino@yahoo.com
}

\begin{abstract}
Exploitation of petroleum began recently in Umutu area, a part of the prolific Niger Delta Oil province, Nigeria. Soil profiles at six locations in this area were investigated to determine the current status of $\mathrm{Cr}, \mathrm{Cu}, \mathrm{Cd}, \mathrm{Co}, \mathrm{Ni}, \mathrm{Zn}, \mathrm{Pb}$, $\mathrm{Mn}$ and $\mathrm{Fe}$, and their bioavailability, in order to have reference data for future monitoring of their bioaccumulation. The procedure used sequential extraction technique. Except for the high contents of $\mathrm{Cu}, \mathrm{Cd}, \mathrm{Co}, \mathrm{Zn}$, and $\mathrm{Pb}$ in $\mathrm{Site}$ $\mathrm{B}$ (an auto-mobile mechanic waste dumpsite), mean metal levels in $\mathrm{mgkg}^{-1}$ for Umutu soils are $\mathrm{Cd}(0.65-1.83), \mathrm{Cu}$ (2.20- 6.30), Pb (4.06-5.90), Cr (7.10-15.60), Ni (1.10-2.00), Zn (33.00- 45.00), Co (0.01- 0.06), Fe (1126.222955.87) and Mn (1.83-18.81). Sequential extraction shows that the bioavailability of Cr except for Site E (all horizons) and Site D $(0-15 \mathrm{~cm})$ are high. That of $\mathrm{Fe}$ is also high at depths of $0-15 \mathrm{~cm}$. Monitoring programme is herein suggested.
\end{abstract}

Keywords: Bioavailability, Metal fractionation, Niger Delta, Sequential extraction, Umutu oil field

\section{Introduction}

Elements pathway of moving from rocks breakdown to plants, then to animals and humans illustrates the natural form of elements availability and therefore the natural control of human health by the solid geology of the environment. In the process of exploitation and consumption of nature's resources, man has over the years modified the availability of elements to humans (sometimes with some health implications) by introducing higher than normal concentrations of elements in the soils of certain localities where industrial, agricultural and other human activities are high. The accumulation can be through the air and/or through spills.

Anthropogenic contamination sources of trace metals in soils include industrial waste, domestic waste and urban infiltration as well as inputs from vehicle exhausts, use of pesticides, burning of fossil fuels, open air incineration of waste and petroleum activities (Enger and Smith, 2006). The most important sources of trace metals include paper mills, organic chemicals, alkalis, petroleum refining, asbestos products, cements, basic steel works, fertilizers, motor vehicles, textile mill products and leather industries.

Most trace elements are essential for the healthy development of plants, animals and humans but they can be toxic and harmful if available in certain concentrations. Accumulation of lead for example causes damage to the brain and kidney while cadmium causes kidney and lung damage as well as high blood pressure (Enger and Smith, 2006). Hence it is advisable to monitor the levels of these trace elements in the soils in areas of high population density and high human activities.

However, knowledge of the total contents of heavy metals present in the soil provides limited information about their behaviour and bioavailability (Iwegbue, 2007). Heavy metals are associated with various soil components in many ways and these determine their reactivity, mobility and bioavailability (Kabala and Singh, 2001, Alloway, 1995). Alloway (1995) described the mechanisms of adsorption and desorption and stated that the processes controlling the availability of both naturally occurring and contaminant (trace and major) elements to plants and their leaching down the soil profile to the groundwater are those which influence the sorption and desorption of these elements within the soil.

Developed countries have a long history of assessing and monitoring the levels of toxic trace elements in their environments. Apart from few recent studies in the urban cities, the status of trace elements in developing countries and especially those areas with the bulk of agricultural activities is rather unknown. This study presents the status of metals and their bioavailability in soils of a rural agricultural area in a developing country (Nigeria). Oil exploitation (with gas being flared) has just started in this area of study and the population is fast increasing. This paper documents the present status of $\mathrm{Cr}, \mathrm{Cu}, \mathrm{Cd}, \mathrm{Co}, \mathrm{Ni}, \mathrm{Zn}, \mathrm{Pb}, \mathrm{Mn}$ and $\mathrm{Fe}$, and provides reference data for future monitoring of their bioaccumulation. 


\subsection{Study Area}

Umutu Field is one of Shell's concessions within the Niger Delta. It lies between latitude $5^{\circ} 35^{\prime}$ and $5^{\circ} 40^{\prime}$ north; and longitude $6^{\circ} 10^{\prime}$ and $6^{\circ} 20^{\prime}$ east (Shell Petroleum Development Company's Grids 418000-428000N and 205000-212000E). It lies within the Niger Delta basin, stretching through Umuaja and Umutu (Figure 1). Accessibility in the area is a major road connecting the oil cities in the Niger Delta with the central regions of Nigeria, and few access routes developed during drilling operation by SPDC. The region is an important wetlands zone referred to as inland area of the coast. The physiography, drainage, climate and vegetation are well described (Orubu, 1981; Etu-Efeotor and Odigi, 1983; Kaizer and Adaikpoh, 2005).

\section{Method of Study}

\subsection{Sampling Method}

Samples were collected from six sites: Umutu outskirt (A), Umutu automobile mechanic waste dumpsite (B), Railway profile (C), Obinomba farmlands (D), Akoko farmlands (E) and Obi-Ebele farmlands (F).

At least five random samples were used as composite sample for any sampling point. Sample points were $10 \mathrm{~m}$ apart within $100 \times 100 \mathrm{~m}$ of each of the sites. At each sampling point, samples were taken from $0-15 \mathrm{~cm}, 15-30 \mathrm{~cm}$ and $30-50 \mathrm{~cm}$ depths. Soils collected from same depths were combined to form the representative sample for that horizon, for that site.

The samples were air-dried. Part of each was sieved for grain-size analysis while the other part was ground to pass through $2 \mathrm{~mm}$ sieve and used for chemical analysis.

\subsection{Analysis Procedure}

The procedure for the chemical analyses is as described by Iwebue, 2007. This procedure separates the metals into fractions as follows: F1= Water soluble metals which are reversible, physically sorbed, and water extractable; F2 = Exchangeable metals which are extractable with $\mathrm{MgCl}_{2}$ at $\mathrm{pH}$ of $7 ; \mathrm{F} 3=$ Specifically sorbed and carbonate bound metals extracted with $\mathrm{NH}_{4} \mathrm{OAc}$ at $\mathrm{pH}$ of 5; F4 = Metals specifically sorbed on iron and manganese oxides extractable with hydroxylamine chloride; F5 = Metals strongly complexed by organic matter and extractable with $\mathrm{H}_{2} \mathrm{O}_{2}$ in $1 \mathrm{~mol} \mathrm{l}^{-1} \mathrm{HNO}_{3}$ and $\mathrm{F} 6=$ Residual metals extractable with $\mathrm{HF}$ and aqua regia.

Two grams of soil was placed in $50 \mathrm{ml}$ polycarbonate centrifuge tube and subjected to the following extraction procedure:

Water soluble fraction F1; the metals in the soil was extracted with $20 \mathrm{ml}$ of deionised water (DI) for $2 \mathrm{~h}$

Exchangeable fraction F2; the metal from F1 residue were extracted with $20 \mathrm{ml}$ of $1 \mathrm{moll}^{-1} \mathrm{MgCl}_{2}$, $\mathrm{pH}$ of 7 for $1 \mathrm{~h}$.

Carbonate- bound fraction F3; the metals from F2 residue were extracted with $20 \mathrm{ml}$ of $1 \mathrm{~mol} \mathrm{l}^{-1} \mathrm{NH}_{4} \mathrm{Ac}$ at $\mathrm{pH}$ of 5 for $5 \mathrm{~h}$.

Fe-Mn oxides-bound fraction F4; the metals from F3 residue were extracted with $20 \mathrm{ml} 0.04 \mathrm{~mol} \mathrm{l}^{-1} \mathrm{NH}_{2} \mathrm{OH} \cdot \mathrm{HCl}$ in $25 \%$ (v/v) HOAc at $96^{\circ} \mathrm{C}$ with occasional agitation.

Organic-bound fraction F5; the metals from $\mathrm{F} 4$ residue were extracted wit $15 \mathrm{ml} \mathrm{30 \%} \mathrm{H}_{2} \mathrm{O}_{2}$ at $\mathrm{pH}$ of 2 (adjusted with $\mathrm{HNO}_{3}$ ) for $5.5 \mathrm{~h}$ (water bath, $85^{\circ} \mathrm{C}$ ). After cooling, $5 \mathrm{ml}$ of $3.2 \mathrm{~mol} \mathrm{l}-1 \mathrm{HH}_{4} \mathrm{OAC}$ in $20 \% \mathrm{HNO}_{3}$ was added and shaken for $30 \mathrm{~min}$ before final dilution to $20 \mathrm{ml}$ with DI.

Residual fraction $\mathrm{F} 6$; the metals from $\mathrm{F} 5$ residue was digested using a $\mathrm{HF}-\mathrm{HCl} / \mathrm{HNO}_{3}$ procedure.

All solid phases (except for F6) were washed with $10 \mathrm{ml}$ of DI water before further extraction. The washes were collected and analysed with supernatant from the previous fraction. After each extraction, the supernatant was separated by centrifugation for $30 \mathrm{~min}$ at $7500 \mathrm{x}$ g. To verify the sum of the metals recovered in the sequential extraction steps, separate total concentrations of the metal were determined on the subsample after an HF/aqua regia digestion.

Quality control was assured by the use of triplicates, standard reference materials ( light sand soil CRM 142R ) and the procedural blanks. For all elements analysed, the coefficient of variation on the triplicates analyses of the soil samples are less than 5\%. The total concentrations of the metals in the supernatants from each step were analysed with Atomic Absorption spectrophotometer (Varian Techtron a 975). The recovery of trace metals in the sequential extraction steps was within $100 \pm 10 \%$.

\section{Result and Discussion}

\subsection{Result}

Soils within the area are characterized by yellowish red colour, $20 \pm 5.5 \%$ clay, $42 \pm 3.8 \%$ silt and $45 \pm 12.2 \%$ sand. Other physicochemical characteristics are documented by Kaizer, and Osakwe (2007) as organic matter $8 \pm$ 2.2 , pH $5.38 \pm 1.56$ and exchangeable cation $16.60 \pm 2.24 \mathrm{Cmol} \mathrm{kg}^{-1}$ 


\subsubsection{Total metal concentration}

The total metal contents and the sum of metal contents from sequential extraction are presented for each horizon and each site in Table 1. Generally, metal contents decrease with depth. Site B has anomalously high concentrations of all the metals except for $\mathrm{Cr}$, Ni and Fe. This could be due to effluents from dumps from auto-mobile mechanic waste. A similar high concentration for some of these elements was reported (Iwebue, 2007) for mechanic dumpsites in Port Harcourt, Nigeria. The concentration for other areas studied are : $\mathrm{Cd}\left(0.65-1.83 \mathrm{mgkg}^{-1}\right) ; \mathrm{Cu}\left(2.20-6.30 \mathrm{mgkg}^{-1}\right)$; $\mathrm{Pb}$ (4.06-5.90 $\left.\mathrm{mgkg}^{-1}\right)$; $\mathrm{Cr}$ (7.10-15.60 $\left.\mathrm{mgkg}^{-1}\right)$; Ni (1.10-2.00 $\left.\mathrm{mgkg}^{-1}\right) ; \mathrm{Zn}$ (33.00-45.00 $\left.\mathrm{mgkg}^{-1}\right)$; Co (0.01-0.06 $\left.\mathrm{mgkg}^{-1}\right) ; \mathrm{Fe}\left(1126.22-2955.87 \mathrm{mgkg}^{-1}\right)$ and $\mathrm{Mn}\left(1.83-18.81 \mathrm{mgkg}^{-1}\right)$. These are within the range for agricultural soils (Lindsay, 1979; Kabata-Pendias and Pendias, 1992; Alloway, 1995; Adriano, 2001).

Metal partition in soil

Results from speciation studies are illustrated in Figures 2-10, and descriptive trend is as thus;

Water soluble fraction (F1)

This fraction represents those metals soluble in water. Metal contents that fractionate in this phase are highly mobile and are readily available to plants and organisms. For the different sites, mean fractional content of the metals are : $\mathrm{Cr}(0.36-2.55 \%$ except in site B with $\mathrm{Cr}$ of $11 \%) ; \mathrm{Zn}(1.27-6.71 \%) ; \mathrm{Cu}(0.62-2.55 \%) ; \mathrm{Cd}$ (6.07-7.71\%); Co (5.56-16.67 \%); Fe (6.57-11.73); Mn (1.47-10.15\%); Pb (1.11-3.99\%); while Ni (0.75\% only occurs in Site B). Generally, all metals content of this phase decrease with depth and below the top horizon (0-15ft).

Exchangeable fraction (F2)

Metal contents that fractionate in this phase have high mobility. Changes in major cationic composition may cause a release due to ionic exchange. They are also readily available to plants and organisms. Besides the mean fractional contents of Co of $9.09 \%$ and $4.76 \%$ for Sites A and B respectively, Co was not partitioned in this geochemical phase. Mean fractional contents of other metals for the sites in this geochemical phase are $\mathrm{Cr}(0.62-3.96 \%)$; Ni (0.00-1.69 \%); Zn (4.05-13.50 \%); Cu (2.21-6.31 \%); Cd (7.96-21.72 \%); Fe (9.73-15.15); Mn (6.29-11.85 \%); Pb (2.36-6.00\%). These values are higher than those of water soluble fraction.

The fractionation of lead and cadmium in F1 and F2 phases where elements are readily available to plants and organisms may call for concern because according to Alloyway (2005), cadmium and lead are the elements in contaminated soils that are considered to constitute the widest possible health risk to humans through the plant uptake-dietary route.

Carbonate-bound fraction (F3)

Metal contents that fractionate in this phase have medium mobility. They are not readily available to plants. Mean fractional contents of metals for the sites in this geochemical phase are $\mathrm{Cr}(4.82-9.42 \%)$; Ni (0.13-6.42\%); $\mathrm{Zn}$ (7.90-18.02 \%); $\mathrm{Cu}$ (3.00-7.74 \%); Cd (8.10-20.72 \%); Fe (11.74-21.37); Mn (6.21-18.04 \%); Pb (6.21-17.73\%). Co did not partition in this fraction except for Site A where $9.09 \%$ of the total content for that site occurs.

Fe-Mn oxides-bound fraction (F4)

Mean fractional contents of metals for the sites in this geochemical phase are $\mathrm{Cr}(20.59-38.67 \%)$; $\mathrm{Ni}$ (11.88-23.21 \%); Zn (29.59-35.33\%); Cu (10.03-22.99\%); Cd (15.29-22.37\%); Co (16.67-62.50\%); Fe (12.95-32.66); Mn (16.42-31.06 \%); Pb (27.09-41.57 \%). Except for Site E and F, the highest percentages of Cr in the soil occur in this phase. Relatively high percentages (only in some cases second to organic-bound phase and / or residual phase) of $\mathrm{Fe}$ and $\mathrm{Mn}$ occur in this phase. Metal contents that fractionate in this phase have medium mobility, and changes in redox condition may cause a release. However, some of these metals precipitate if sulphide minerals present are insoluble.

Organic-bound fraction (F5)

Metal contents that fractionate in this phase have medium mobility and with time, decomposition/ oxidation of organic matter matter will occur. Mean fractional contents of metals for the sites in this geochemical phase are $\mathrm{Cr}$ (15.74-32.43 \%); Ni (2.03-5.26 \%); Zn (8.42-12.78\%); Cu (20.77- 47.53\%); Cd (2.55-11.05\%); Co (25.00 $77.78 \%)$; Fe (28.27- 44.39); $\mathrm{Mn}$ (21.33-35.91\%); $\mathrm{Pb}$ (3.41-11.11\%). Relatively high percentages of $\mathrm{Cr}$ occur in this phase.

\section{Residual fraction (F6)}

Metal contents that fractionate in this phase are fixed in the crystal lattice, have low mobility and can only be available after weathering or decomposition of the crystals. 
Mean fractional contents of metals for the sites in this geochemical phase are $\mathrm{Cr}$ (19.81-54.29\%); Ni (66.42-83.89 \%); Zn (23.34-40.61\%); $\mathrm{Cu}$ (30.10-53.55\%); Cd (25.60 - 53.50\%); Co (0.00-50.00\%); Fe (26.01-42.64 \%); $\mathrm{Mn}$ (20.14-30.99 \%); $\mathrm{Pb}$ (36.74-48.19\%). Ni, Cu, $\mathrm{Zn}, \mathrm{Cd}$ and $\mathrm{Pb}$ have their highest percentages in this phase.

3.1.2 Mobility factors of metals

The mobility factor was calculated according to Narwal et al., 1999 and Kabala and Singh, 2001 as

$(\mathrm{F} 1+\mathrm{F} 2+\mathrm{F} 3) \mathrm{X} 100 \% /(\mathrm{F} 1+\mathrm{F} 2+\mathrm{F} 3+\mathrm{F} 4+\mathrm{F} 5+\mathrm{F} 6)$

The mobility factors for sites and depths are shown in Table 2.

Except for Site E (all horizons) and Site D $(0-15 \mathrm{~cm})$, the mobility factors of Cd are high in Umutu soils. That of Fe is also high at depth $0-15 \mathrm{~cm}$. High values of mobility factor for a heavy metal is an evidence of relative high mobility and bio-avaiability (Kabala and Singh, 2001). Mobility factors decrease with depth for all metals and sites except for $\mathrm{Cr}$ (Site C and F), Cu (Site A), Cd (Site A), Pb (Site C), Mn (Site A, C, D, E and F) and Co (all sites and all horizons).

\subsection{Discussion}

Site B is an auto-mobile mechanic waste dumpsite and its soil has high metal contents which may have been due to the waste. This should be noted in any future consideration of these results as reports from a baseline study. The Cd content for the Fe-Mn oxide phase is relatively high. Similar results have been reported by Horsefall and Spiff (2005), and Osakwe and Egharevba (2008). This fraction changes with variation in redox conditions becoming more soluble under reducing conditions and less soluble under oxidizing ones. Therefore, an increase in reducing conditions of the soil could increase metal mobility with increased toxicity. The contamination risk of the metals is in the order of $\mathrm{Cu}<\mathrm{Ni}<\mathrm{Cd}<\mathrm{Fe}<\mathrm{Mn}<\mathrm{Cr}<\mathrm{Zn}<\mathrm{Pb}<\mathrm{Co}$. Relatively significant amount of $\mathrm{Cu}$ (20.77- 47.53\%) occurs in the organic fraction. High $\mathrm{Cu}$ in organic fractions of soil extracts have been reported by Osakwe and Egharevba (2008), Tessier et al. (1980), Ma and Rao (1997) and Ryan et al. (2002). This is expected because of the high values for formation constant of $\mathrm{Cu}$-organic complexes.

From the trends of fractional distribution (Figures 2-10) only $\mathrm{Mn}, \mathrm{Cu}$ and $\mathrm{Fe}$ show similar tends of Residual > Organic complexed $>$ Oxide extractable $>$ Carbonate bound $>$ Exchangeable $>$ Water soluble. This trend is similar to reports of Iwebue (2007).

The highest bioavailable fractions of the metals $\mathrm{Cr}$ (Site $\mathrm{B}$ ), $\mathrm{Ni}$ and $\mathrm{Cu}$ (site $\mathrm{C}$ ), $\mathrm{Fe}$ and $\mathrm{Pb}$ (Site F) occur in depths of $0-15 \mathrm{~cm}$ (Table 1). Cd and Co have their highest bioavailable fractions in depths of $15-30 \mathrm{~cm}$ in site B and A respectively. Only $\mathrm{Mn}$ has its highest bioavailable fraction in depths of 30- 45cm (Site E). This shows that these metals are most mobile at the surface horizons. Similar results have been reported by Iwegbue (2005), Kuo et al. (1983), and Kabala and Sigh (2005). These Authors emphasized the predominance of heavy metal accumulation in the surface horizons and the lack of metal redistribution in soil profile. The $0.01-0.06 \mathrm{mgkg}^{-1}$ metal content of Co (apart from the waste dumpsite) is low and Co is not bioavailable above the depth of $30 \mathrm{~cm}$ in Sites D, E, and F. Fe has high metal content (1126.22-2955.87 $\left.\mathrm{mgkg}^{-1}\right)$ and also is highly bioavailable with mobility factors ranging from 25.84 to 33.69 .

\section{Conclusion}

Agricultural areas can be prone to heavy metal contamination when industrial and mining activities are introduced. The consequences of bioaccumulation of these heavy metals are obvious. This paper documents the current status of $\mathrm{Cr}, \mathrm{Cu}, \mathrm{Cd}, \mathrm{Co}, \mathrm{Ni}, \mathrm{Zn}, \mathrm{Pb}, \mathrm{Mn}$ and $\mathrm{Fe}$ as well as their bioavailability, and provides reference data for future monitoring of their bioaccumulation in soils of Umutu Oil Field, Niger Delta Nigeria. As oil flaring unfortunately continues in Nigeria, future studies should be those that measure changes of metal contents, physico-chemical parameters, soil organic content, $\mathrm{pH}, \mathrm{PAHs}$, conductivity, temperature, etc. as well as assessing the chronic and acute effects of the contaminants on the terrestrial ecosystem. Sampling should be done on a seasonal basis of 4 months in wet season and 4 months in dry season. Sampling points should be radial with progressively increasing radii of 1, 50,100, 150 and 200 kilometers from the flaring point. Samples should be collected from depths of $15 \mathrm{~cm}$ (where most of the plants' roots are).

\section{References}

Adriano, D. C. (2001). Trace Elements in terrestrial Environments ( $2^{\text {nd }}$ ed.), New York: Springer-Verlag.

Alloway, B. J. (Ed.) (1995). Heavy metals in Soils. (2 ${ }^{\text {nd }}$ ed.) London: Blackie Academic and Professional.

Enger, E. D. \& Smith, B. F. (2002). Environmental Science. ( $8^{\text {th }}$ ed.). McGraw-Hill. 
Etu-Efeotor, J. O., \& Odigi, M. I. (1983). Water supply problems in Eastern Niger Delta: Nigeria Journal of Mining Geology, 20, 183-193.

Horsefall, M.. \& Spiff, A. (2005). Speciation and bioavailability of heavy metals in sediments in Diobu River, Port Harcourt, Nigeria. European Journal of Sciecientific research, (3). 20-36.

Iwebue, C. M. A. (2007). Metal fractionation in soil profiles at automobile mechanic waste dumps. Waste management and Research, 25, 585-593.

Kabala, C., \& Singh, B. R. (2001). Fractionation and mobility of copper, lead and zinc in soil profiles in the vicinity of a copper smelter. Journal of Environmental Quality, 30, 485-495.

Kabata-Pendias, A. \& Pendias, I. I. (1992). Trace elements in soils and plants. ( $2^{\text {nd }}$ edn.). Boca Ration Fl.: CRC Press

Kaizer, A. N., \& Osakwe S A. (2007). Water chemistry in the Upper and Middle Ethiope River, Southwest Nigeria. Nigerian Journal of Science and Environment, 6, 146-157.

Kaizer, A.N., \& Adaikpoh E.O. (2005). Some geotechnical properties of soils around Umutu and environs, southwest Nigeria. Journal of Applied Science \& Environmental. Management, 10, (4) 41-45.

Kuo, S., Heilman, P. E. \& Baker, A. S. (1983). Distribution and forms of copper, zinc, cadmium, iron and manganese in soils near a copper smelter. Journal of Soil Science, 135. 101 - 109.

Lindsay, W. L. (1979). Chemical equilibrian in soils. New York: John Wiley and Sons.

Ma, L. Q. \& Rao, G. N. (1997). Chemical fractionation of $\mathrm{Cd}, \mathrm{Cu}, \mathrm{Ni}$ and $\mathrm{Zn}$ contaminated soils. Journal of Environmental Quality, 26. 259-264.

Narwal, R. P., Singh, B. R., \& Salbu, B. (1999). Association of cadmium, zinc, copper and nickel with components in naturally heavy metal rich soils studied by parallel and sequential extraction. Communication in Soil Science and Plant Analysis. 30. 1209-1230.

Orubu, A. O. (1981). A Short Geography of Bendel State. Ibadan: University Press, (Chapter 3).

Osakwe, S. A., \& Egharevba, F. (2008). Sequential fractionation of cadmium, copper, lead and chromium in soils around municipal solid waste dumps in Agbor, Nigeria. Journal of chemical Society of Nigeria, 33(2). 139 - 147.

Ryan, P. C., Wall, A. J., Hiller, S., \& Clerk, L. (2002). Insights into sequential chemical extraction procedure for quantitative XRD: a study of trace metal partitioning in soils and sediments related to frog malformation. Chemical Geology, 184. 337-357.

Tessier, A., Campbell P. G. C., \& Bisson, M. (1980). Trace metal speciation in the Yamaska and St. Francis River (Quebec). Canadian Journal of Earth Science, 17, 90-105. 
Table 1. Total metals contents in soils of Umutu area and sum of their sequential extracts

\begin{tabular}{|c|c|c|c|c|c|c|c|c|c|c|}
\hline \multicolumn{11}{|c|}{ Total metal content contents $\left(\mathrm{mgkg}^{-1}\right)$. } \\
\hline & Depth $(\mathrm{Cm})$ & $\mathrm{Cd}$ & $\mathrm{Cu}$ & $\mathrm{Pb}$ & $\mathrm{Cr}$ & $\mathrm{Ni}$ & $\mathrm{Zn}$ & $\mathrm{Co}$ & $\mathrm{Fe}$ & $\mathrm{Mn}$ \\
\hline \multirow{3}{*}{ SITE A } & $0-15$ & 1.43 & 3.22 & 4.38 & 12.30 & 1.50 & 45.00 & 0.05 & 2114.38 & 15.12 \\
\hline & $15-30$ & 1.41 & 3.26 & 5.26 & 10.60 & 1.30 & 42.30 & 0.04 & 2955.87 & 15.68 \\
\hline & $30-50+$ & 0.95 & 3.34 & 5.56 & 7.60 & 1.30 & 42.30 & 0.05 & 1806.66 & 14.33 \\
\hline \multirow{3}{*}{ SITE B } & $0-15$ & 34.00 & 386.12 & 496.85 & 14.60 & 1.90 & 430.95 & 0.14 & 2813.44 & 14.76 \\
\hline & $15-30$ & 41.22 & 362.77 & 466.61 & 8.60 & 1.80 & 462.86 & 0.14 & 2098.11 & 13.00 \\
\hline & $30-50+$ & 36.75 & 320.34 & 400.12 & 8.20 & 1.80 & 431.43 & 0.17 & 2629.60 & 8.92 \\
\hline \multirow{3}{*}{ SITE C } & $0-15$ & 1.83 & 6.30 & 5.90 & 10.70 & 2.00 & 46.00 & 0.05 & 2053.17 & 16.01 \\
\hline & $15-30$ & 1.28 & 6.10 & 5.63 & 10.80 & 1.90 & 43.20 & 0.06 & 2099.85 & 13.38 \\
\hline & $30-50+$ & 1.62 & 5.56 & 5.30 & 11.00 & 1.80 & 42.00 & 0.05 & 2006.28 & 10.22 \\
\hline \multirow{3}{*}{ SITE D } & $0-15$ & 1.04 & 3.52 & 5.30 & 9.20 & 1.50 & 41.60 & 0.03 & 1931.21 & 17.98 \\
\hline & $15-30$ & 0.94 & 3.34 & 4.98 & 8.20 & 1.40 & 40.80 & 0.03 & 2183.58 & 17.27 \\
\hline & $30-50+$ & 0.83 & 3.06 & 4.73 & 7.10 & 1.20 & 40.80 & 0.03 & 1967.22 & 13.55 \\
\hline \multirow{3}{*}{ SITE E } & $0-15$ & 0.83 & 2.75 & 5.21 & 15.20 & 1.40 & 38.20 & 0.03 & 2399.88 & 18.81 \\
\hline & $15-30$ & 0.82 & 3.56 & 4.73 & 15.60 & 1.30 & 34.40 & 0.02 & 2381.46 & 15.15 \\
\hline & $30-50+$ & 0.65 & 2.20 & 4.06 & 14.60 & 1.10 & 33.00 & 0.05 & 1555.93 & 15.00 \\
\hline \multirow{3}{*}{ SITE F } & $0-15$ & 1.40 & 3.50 & 5.15 & 12.50 & 1.70 & 42.50 & 0.01 & 1300.47 & 4.06 \\
\hline & $15-30$ & 0.96 & 3.18 & 4.22 & 8.30 & 1.60 & 40.50 & 0.03 & 1231.48 & 1.83 \\
\hline & $30-50+$ & 0.93 & 3.06 & 4.07 & 7.90 & 1.40 & 39.40 & 0.06 & 1126.22 & 2.08 \\
\hline \multicolumn{11}{|c|}{ Sum of fractions F1 -F6 $\left(\mathrm{mgkg}^{-1}\right)$} \\
\hline & & $\mathrm{Cd}$ & $\mathrm{Cu}$ & $\mathrm{Pb}$ & $\mathrm{Cr}$ & $\mathrm{Ni}$ & $\mathrm{Zn}$ & $\mathrm{Co}$ & $\mathrm{Fe}$ & $\mathrm{Mn}$ \\
\hline \multirow{3}{*}{ SITE A } & $0-15$ & 1.24 & 3.36 & 3.21 & 13.10 & 1.50 & 44.00 & 0.06 & 2105.62 & 16.67 \\
\hline & $15-30$ & 1.49 & 3.10 & 4.88 & 9.40 & 1.20 & 41.00 & 0.03 & 2961.56 & 15.13 \\
\hline & $30-50+$ & 0.98 & 3.06 & 5.41 & 8.20 & 1.40 & 40.40 & 0.06 & 1799.52 & 11.04 \\
\hline \multirow{3}{*}{ SITE B } & $0-15$ & 32.55 & 380.54 & 500.17 & 14.50 & 1.90 & 422.61 & 0.13 & 2808.47 & 19.03 \\
\hline & $15-30$ & 38.64 & 361.43 & 460.07 & 8.30 & 1.70 & 450.62 & 0.14 & 3008.80 & 19.04 \\
\hline & $30-50+$ & 32.66 & 322.00 & 404.43 & 7.90 & 1.70 & 438.22 & 0.15 & 2625.41 & 10.98 \\
\hline \multirow{3}{*}{ SITE C } & $0-15$ & 1.95 & 6.24 & 5.24 & 10.20 & 2.00 & 44.30 & 0.04 & 2041.79 & 12.16 \\
\hline & $15-30$ & 1.44 & 5.90 & 5.55 & 10.00 & 2.00 & 41.80 & 0.08 & 2098.89 & 11.79 \\
\hline & $30-50+$ & 1.62 & 5.30 & 5.23 & 10.60 & 1.90 & 40.50 & 0.05 & 2014.33 & 10.06 \\
\hline \multirow{3}{*}{ SITE D } & $0-15$ & 1.14 & 3.58 & 5.15 & 8.90 & 1.60 & 41.40 & 0.02 & 1929.37 & 20.91 \\
\hline & $15-30$ & 1.00 & 3.20 & 4.63 & 8.20 & 1.40 & 41.20 & 0.03 & 2166.57 & 20.53 \\
\hline & $30-50+$ & 0.98 & 2.88 & 4.60 & 7.00 & 1.30 & 40.20 & 0.04 & 1971.65 & 18.54 \\
\hline \multirow[b]{3}{*}{ SITE E } & $0-15$ & 0.84 & 2.60 & 5.06 & 14.30 & 1.50 & 37.00 & 0.03 & 2395.27 & 21.19 \\
\hline & $15-30$ & 0.88 & 2.54 & 4.69 & 15.00 & 1.30 & 33.60 & 0.01 & 2363.52 & 11.73 \\
\hline & $30-50+$ & 0.75 & 2.18 & 3.77 & 14.80 & 1.00 & 31.50 & 0.05 & 1575.66 & 9.61 \\
\hline \multirow[b]{3}{*}{ SITE F } & $0-15$ & 1.32 & 3.54 & 5.10 & 12.50 & 1.80 & 42.80 & 0.01 & 1297.46 & 5.73 \\
\hline & $15-30$ & 1.06 & 3.16 & 4.28 & 8.50 & 1.60 & 40.10 & 0.03 & 1213.93 & 2.89 \\
\hline & $30-50+$ & 0.98 & 3.00 & 4.12 & 7.90 & 1.60 & 39.50 & 0.05 & 1114.10 & 5.08 \\
\hline
\end{tabular}


Table 2. Mobility factor for metals in soils of Umutu and environs, northwest Nigeria

\begin{tabular}{|c|c|c|c|c|c|c|c|c|c|}
\hline \multirow[b]{2}{*}{ Depth $(\mathrm{Cm})$} & \multicolumn{3}{|c|}{$\mathrm{Cr}$} & \multicolumn{3}{|c|}{$\mathbf{N i}$} & \multicolumn{3}{|c|}{ Cd } \\
\hline & \multirow[t]{2}{*}{$0-15$} & \multirow[t]{2}{*}{$15-30$} & \multirow[t]{2}{*}{$30-45$} & \multirow[t]{2}{*}{$0-15$} & \multirow[t]{2}{*}{$15-30$} & \multirow[t]{2}{*}{$30-45$} & \multirow[t]{2}{*}{$0-15$} & \multirow[t]{2}{*}{$15-30$} & \multirow[t]{2}{*}{$30-45$} \\
\hline Site & & & & & & & & & \\
\hline $\mathrm{A}$ & 8.47 & 11.91 & 6.71 & 1.34 & 0.00 & 0.00 & 42.98 & 39.6 & 26.53 \\
\hline $\mathrm{B}$ & 26.92 & 12.65 & 7.59 & 9.47 & 8.24 & 5.88 & 54.36 & 54.84 & 39.16 \\
\hline $\mathrm{C}$ & 11.86 & 11.90 & 11.04 & 10.00 & 2.00 & 1.05 & 43.37 & 41.67 & 43.21 \\
\hline $\mathrm{D}$ & 10.11 & 16.08 & 5.14 & 3.75 & 3.57 & 8.46 & 33.33 & 33.66 & 18.18 \\
\hline $\mathrm{E}$ & 8.39 & 8.53 & 10.2 & 9.33 & 6.92 & 1.00 & 28.92 & 26.14 & 16.00 \\
\hline \multirow[t]{2}{*}{$\mathrm{F}$} & 8.40 & 8.47 & 10.25 & 3.89 & 9.38 & 3.75 & 43.18 & 37.74 & 40.40 \\
\hline & \multicolumn{3}{|c|}{$\mathbf{C u}$} & \multicolumn{3}{|c|}{$\mathrm{Zn}$} & \multicolumn{3}{|c|}{$\mathbf{F e}$} \\
\hline $\operatorname{Depth}(\mathrm{Cm})$ & \multirow[t]{2}{*}{$0-15$} & \multirow[t]{2}{*}{$15-30$} & \multirow[t]{2}{*}{$30-45$} & \multirow[t]{2}{*}{$0-15$} & \multirow[t]{2}{*}{$15-30$} & \multirow[t]{2}{*}{$30-45$} & \multirow[t]{2}{*}{$0-15$} & \multirow[t]{2}{*}{$15-30$} & \multirow[t]{2}{*}{$30-45$} \\
\hline Site & & & & & & & & & \\
\hline A & 9.85 & 9.97 & 4.92 & 25.91 & 21.81 & 12.72 & 31.68 & 33.69 & 30.90 \\
\hline $\mathrm{B}$ & 14.17 & 8.33 & 10.00 & 30.91 & 20.00 & 16.36 & 24.50 & 31.04 & 25.14 \\
\hline $\mathrm{C}$ & 16.53 & 11.68 & 8.3 & 38.2 & 38.18 & 31.93 & 28.34 & 29.41 & 30.63 \\
\hline $\mathrm{D}$ & 15.08 & 8.15 & 5.21 & 24.54 & 17.28 & 20.00 & 21.38 & 32.63 & 27.88 \\
\hline$E$ & 13.46 & 4.72 & 7.76 & 26.35 & 25.45 & 14.54 & 32.99 & 25.84 & 19.69 \\
\hline \multirow[t]{2}{*}{$\mathrm{F}$} & 12.68 & 5.99 & 1.67 & 25.46 & 7.28 & 9.09 & 40.86 & 30.28 & 27.66 \\
\hline & \multicolumn{3}{|c|}{ Co } & \multicolumn{3}{|c|}{ Mn } & \multicolumn{3}{|c|}{$\mathbf{P b}$} \\
\hline $\operatorname{Depth}(\mathrm{Cm})$ & \multirow[t]{2}{*}{$0-15$} & $15-30$ & $30-45$ & $0-15$ & $15-30$ & $30-45$ & $0-15$ & $15-30$ & $30-45$ \\
\hline Site & & & & & & & & & \\
\hline $\mathrm{A}$ & 16.67 & 33.33 & 16.67 & 24.36 & 26.57 & 25.63 & 16.20 & 12.30 & 9.24 \\
\hline B & 12.9 & 14.29 & 20.00 & 30.74 & 28.73 & 28.23 & 22.45 & 21.43 & 22.45 \\
\hline $\mathrm{C}$ & 0.00 & 12.50 & 20.00 & 24.18 & 26.55 & 33.20 & 25.00 & 25.59 & 23.33 \\
\hline $\mathrm{D}$ & 0.00 & 0.00 & 25.00 & 26.06 & 29.08 & 28.43 & 18.45 & 18.36 & 16.3 \\
\hline $\mathrm{E}$ & 0.00 & 0.00 & 20.00 & 30.11 & 32.98 & 39.13 & 20.36 & 16.20 & 6.10 \\
\hline F & 0.00 & 0.00 & 20.00 & 26.35 & 33.56 & 33.46 & 30.59 & 25.47 & 11.17 \\
\hline
\end{tabular}




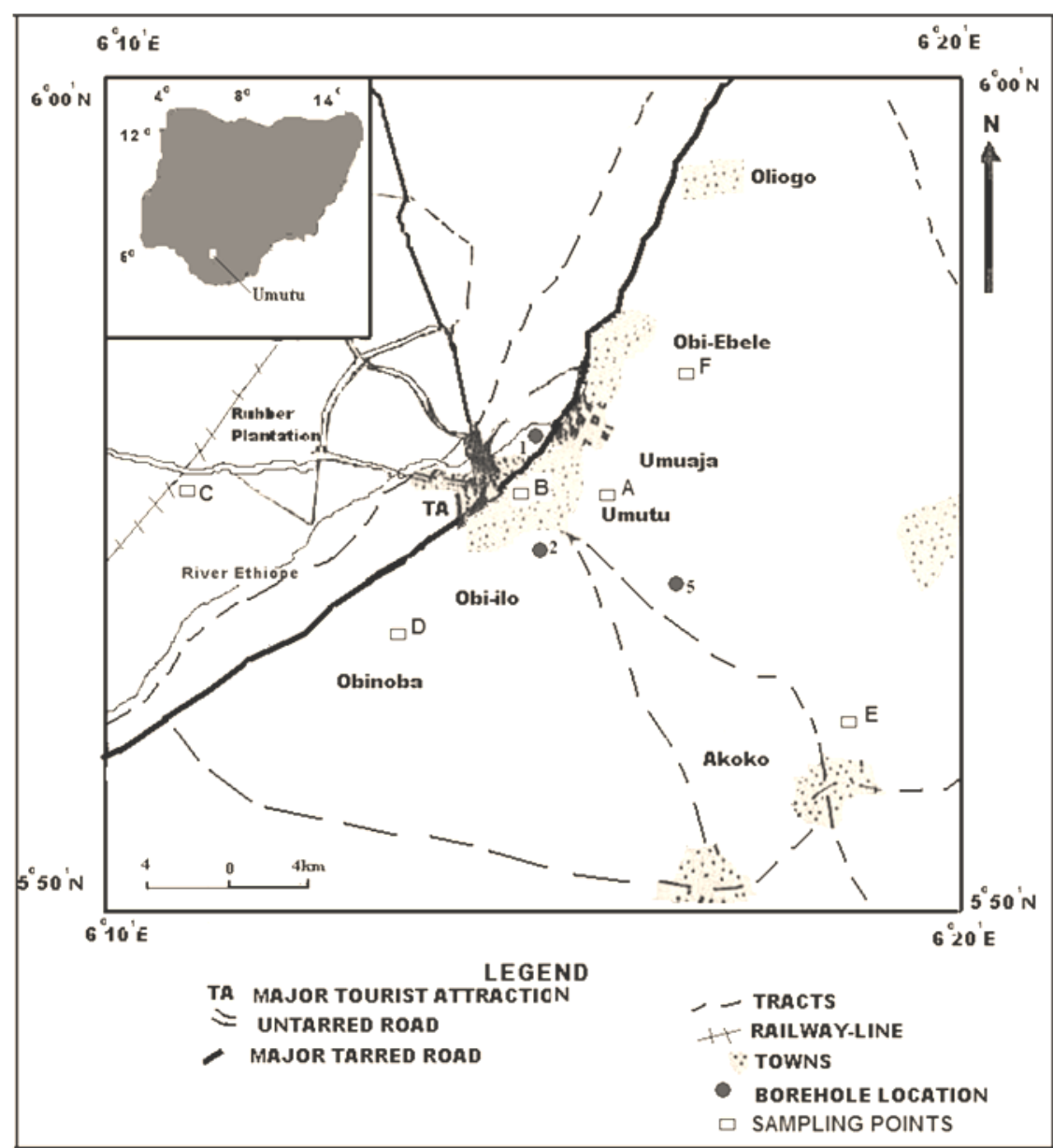

FIGURE 1. MAP OF UMUTU AREA

Figure 1. Map of Umutu Area

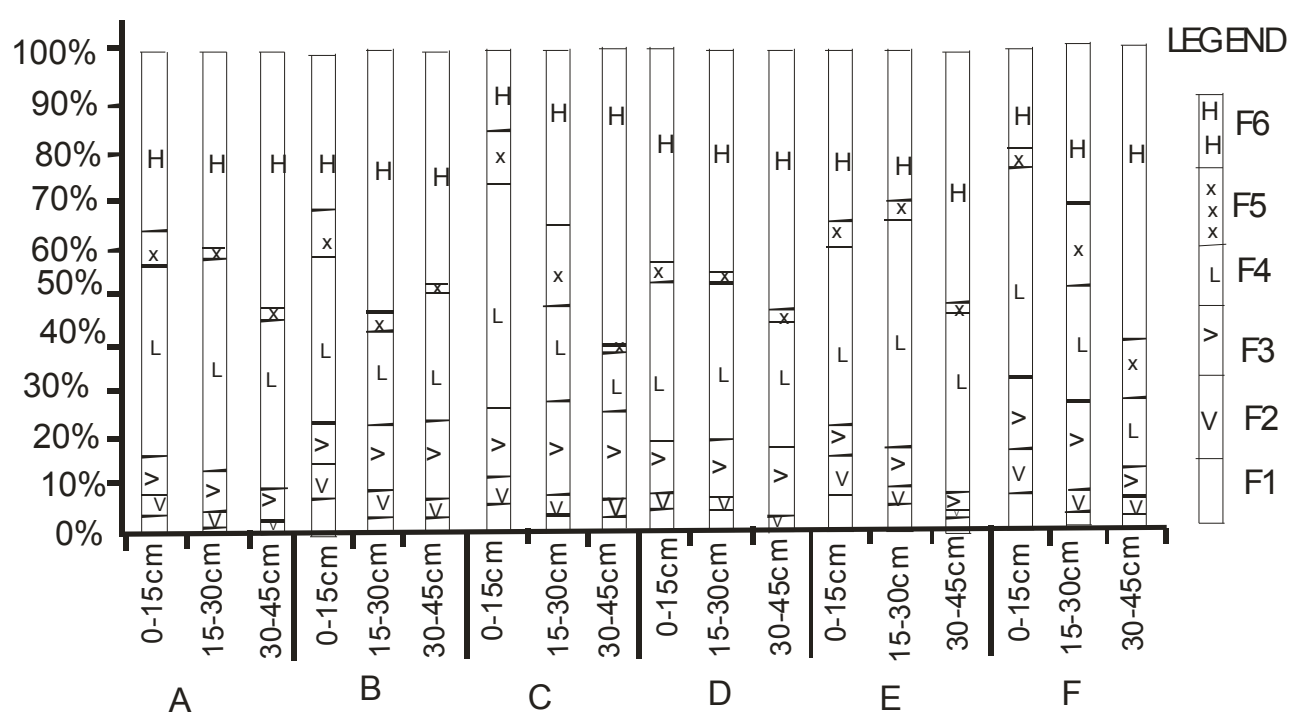

Figure 2. Percentage of lead in various geochemical phases of the soil from sequential extraction 


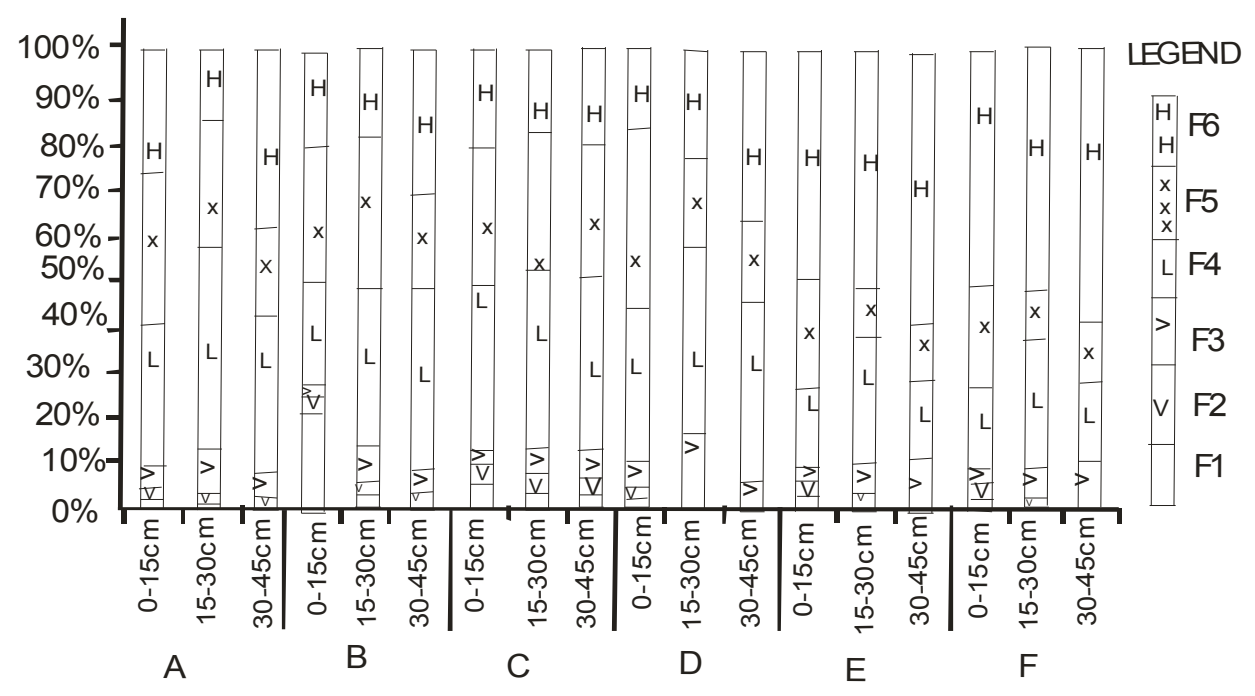

Figure 3. Percentage of chromium in various geochemical phases of the soil sequential extraction

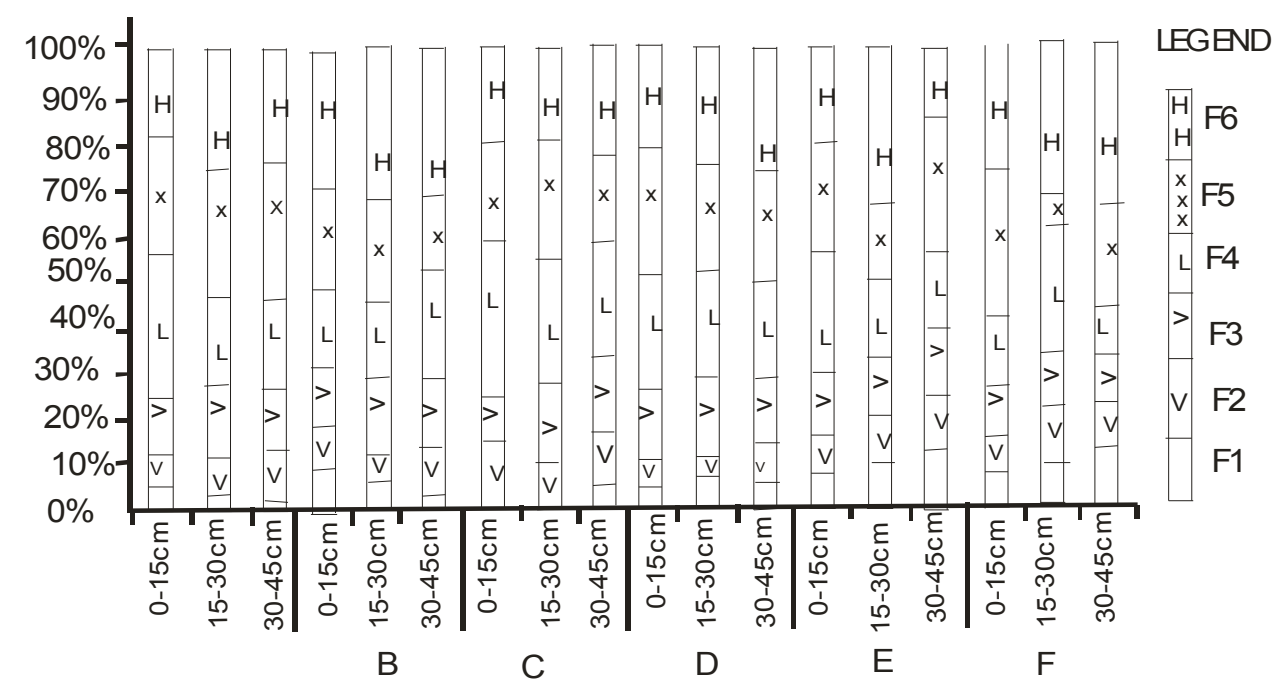

Figure 4. Percentage of manganese in various geochemical phases of the soil from sequential extraction

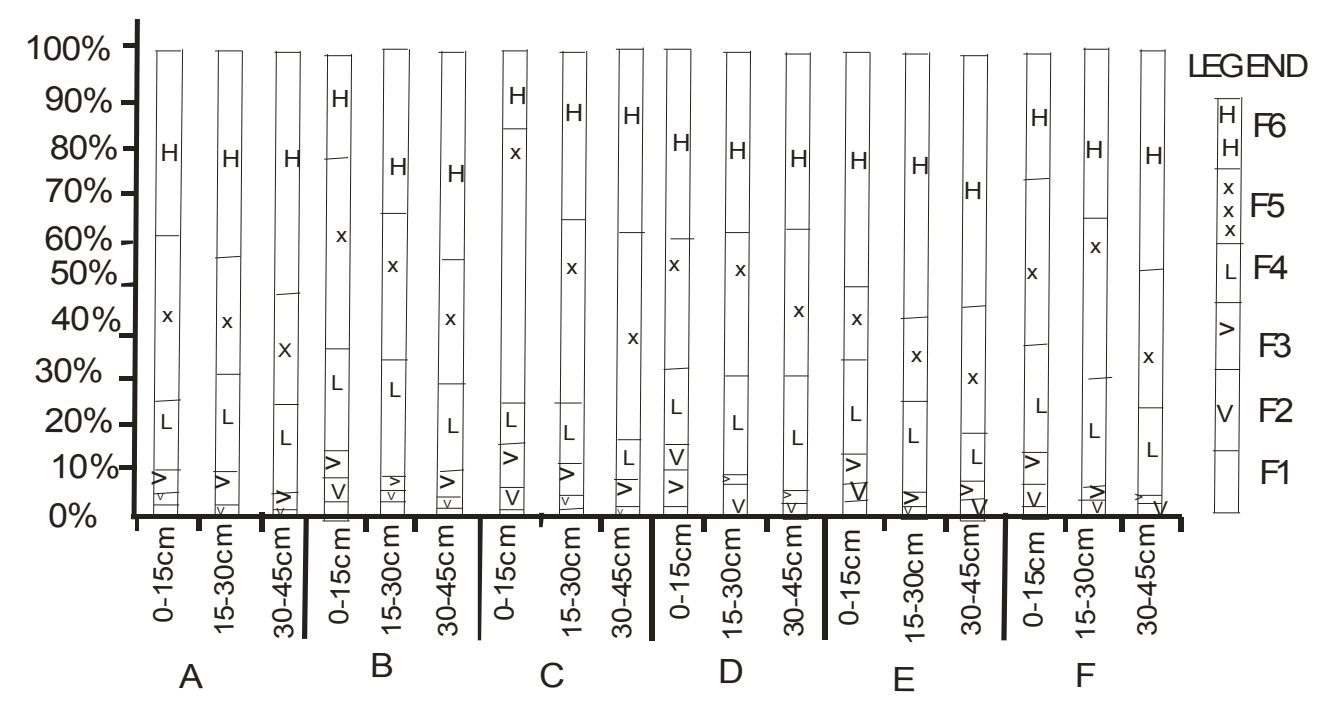

Figure 5. Percentage of copper in various geochemical phases of the soil from sequential extraction 


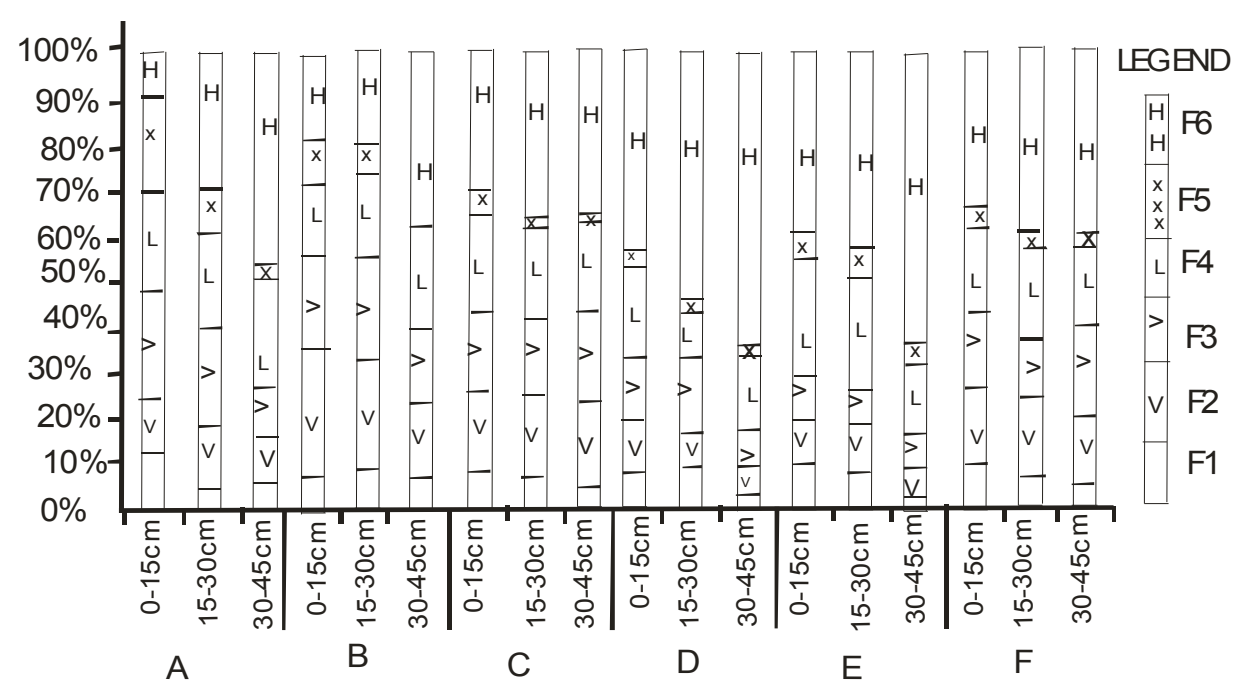

Figure 6. Percentage of cadmium in various geochemical phases of the soil sequential extraction

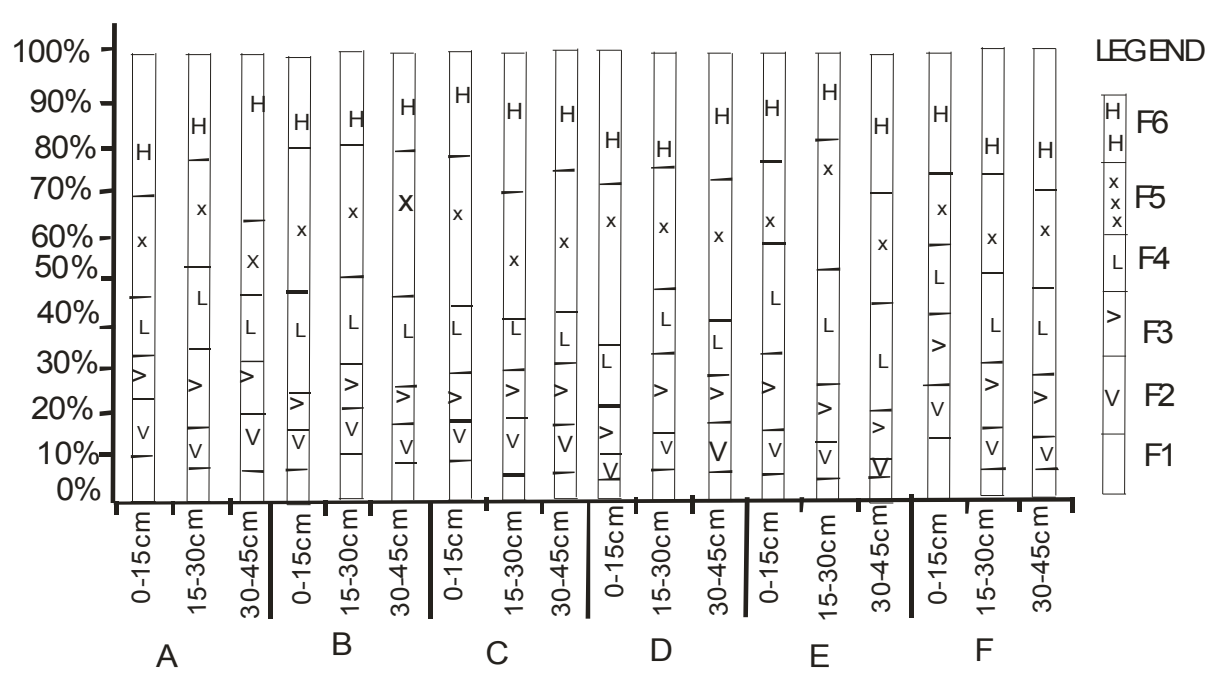

Figure 7. Percentage of iron in various geochemical phases of the soil sequential extraction

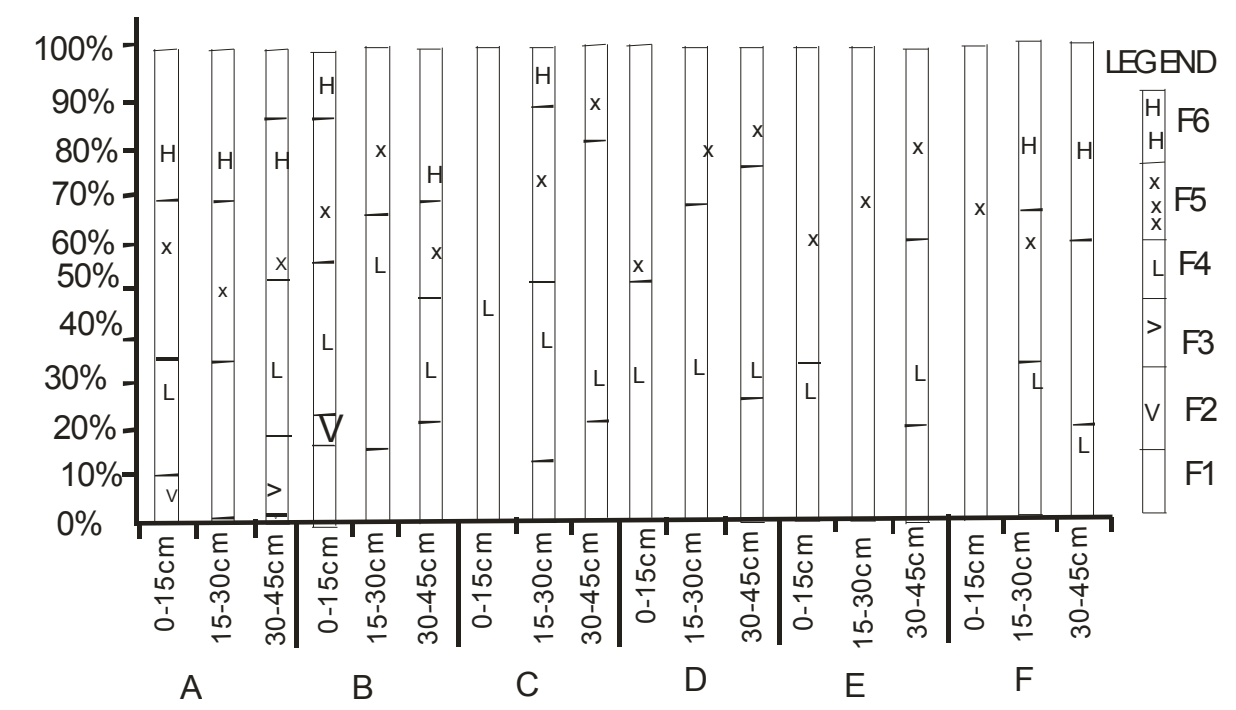

Figure 8. Percentage of cobalt in various geochemical phases of the soil sequential extraction 


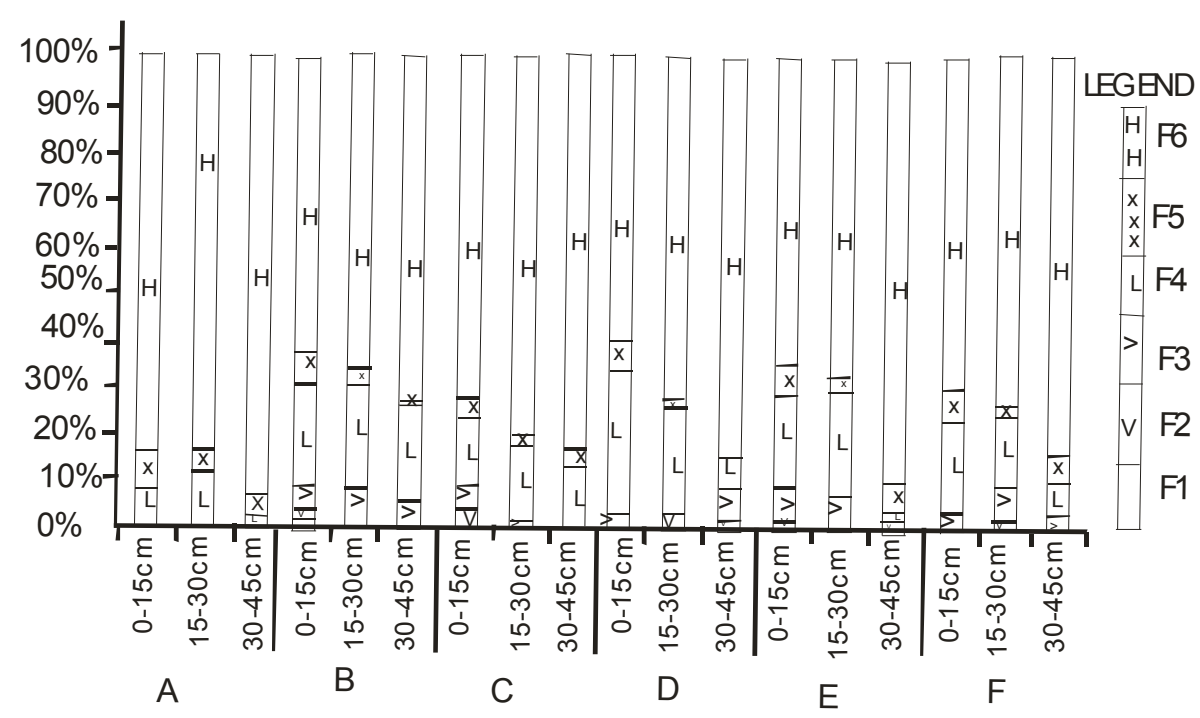

Figure 9. Percentage of nickel in various geochemical phases of the soil from sequential extraction

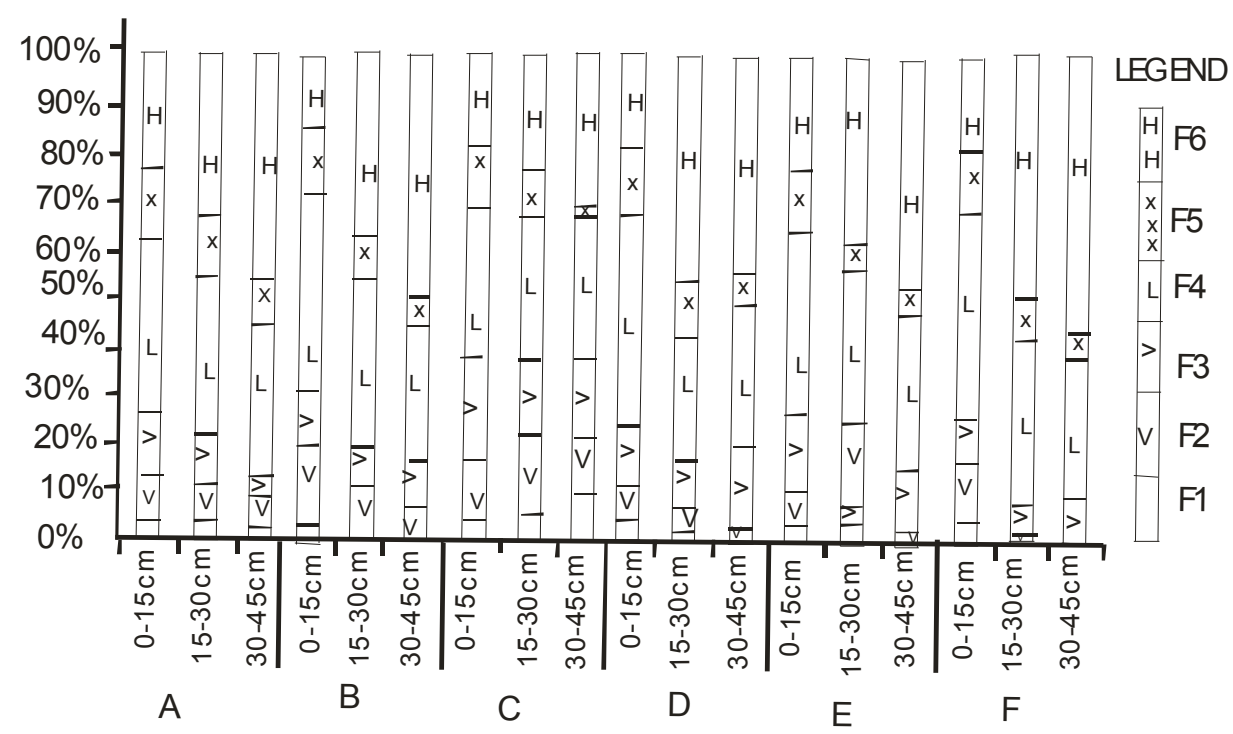

Figure 10. Percentage of zinc in various geochemical phases of the soil from sequential extraction 